DOI: 10.20472/IAC.2018.042.013

\title{
FAZIL GÖKGÖZ
}

Ankara University, Turkey

ENGIN YALÇIN

Ankara University, Turkey

\section{INVESTIGATING THE EFFICIENCIES OF WORLD CUP TEAMS VIA DEA APPROACH}

\begin{abstract}
:
It is crucial to analyze football teams since football has increasingly become a significant industry within the economy. Data Envelopment Analysis (DEA) has been applied to many branches and especially to football. This paper investigates the technical efficiency levels of national teams participating in World Cup 2014 to shed light on the sport performance. Input oriented CCR/BCC model and super efficiency analyses have been used to investigate the football efficiencies. In this study, passes completed, attempts on target and possession are used as input while the only output is goal scored. The results have illustrated that World Cup winner Germany is found as efficient on both CCR and BCC model. On the other hand, only four teams are technically efficient within 32 teams while nine teams have demonstrated pure efficiency. Colombia is the most efficient team for both CCR and BCC super efficiency model. In this regard, we may conclude that efficiency would be a viable instrument in analyzing the football teams.
\end{abstract}

\section{Keywords:}

DEA, World Cup, Football Efficiency.

JEL Classification: C60, C61, L83 


\section{Introduction}

Football is one of the most exciting sport branch for the people. The football has increasingly become a substantial industry within the world economy.

Data Envelopment Analysis (DEA) is a non-parametric efficiency technique based on measuring relative efficiency of decision making units (DMUs) that have multiple inputs and outputs. The concept of data envelopment analysis (DEA) was first introduced by Charnes et al. (1978) (Kao and Liu, 2014: 90). DEA provides analysts with target values that could convert inefficient DMUs into efficient DMUs (Iribarren et al., 2014: 527).

Measuring performance of DMUs is significant due to some reasons (Sport England, 2001: 3):

- If you couldn't measure outcomes, you couldn't reveal the situation properly.

- If you couldn't determine achievement, you couldn't reward it.

- If you couldn't reward success, you're likely rewarding failure.

- If you couldn't determine deficiency, you couldn't improve it.

Academic interest in the professional team sports dates back as far as the mid-1950s. The efficiency of football associations have already been analyzed in the literature.

Barros and Barrio (2008) examines the technical efficiency of the English football Premier League. Villa and Lozano (2016) introduces a novel approach called network DEA to evaluate the scoring efficiency of football teams in a match at La Liga. Bosca et al, (2009) investigates technical efficiency of Italian and Spanish football for three seasons.

Kern (2012) introduced two-stage data envelopment analysis to measure the efficiency of English Premier League football teams. Sanchez (2007) applied three-stage-DEA model to Spanish La Liga separating the teams' economic behavior into three elements. Tiedemann et al, (2011) employ Metafrontier DEA approach to measure players' efficiency scores depending on their playing positions. Barros and Leach (2006) applies DEA method to investigate the performance of English Premier League football clubs taking into consideration sport and financial variables.

The goal of this paper is to investigate the efficiency values of national teams participating in 2014 World Cup. In this regard, CCR, BCC versions and super efficiency model of DEA technique have been applied to national teams so as to find out the efficiency score levels. The main contribution of this study to literature is that there have been no study applied to World Cup teams.

The rest of the study is organized as follows; section two briefly mentions information about World Cup and section three presents the DEA model. Section four illustrates empirical results; finally, section five provides the concluding remarks. 


\section{Information about World Cup}

From the first World Cup in 1930 at which sixteen nations participated, and for which there was no real qualifying stage, World Cup has enlarged to include thirty-two teams in its quadrennial final, based upon worldwide qualifying phases in which every national team in the world can participate (Tomlinson and Young, 2006: 2).

Uruguay was the first nation to win a World Cup winning the inaugural tournament in 1930 which they also hosted. World Cup tournament was not held between 1938 and 1950 due to World War II. They won their second World Cup in 1950 following World War II. Uruguay beat Brazil 2-1 in the final at the Estádio do Maracanã in Rio de Janeiro which had the highest ever attendance to a football match with a crowd of 173,850 people.

Brazil is the most successful nation in world football having won the World Cup 5 times. They have also won the Confederations cup on 4 occasions. Brazil stands alone as the only nation to have played in every World Cup. Brazil is the only country to have won the World Cup on four different continents (1958 in Europe, 1962 in South America, 1970 and 1994 in North America and 2002 in Asia). Italy is the most successful European soccer nation having won the World Cup on four occasions and also reached two finals they were unsuccessful in (Wheelwright, 2014: 7).

World Cup titles won by countries from 1930 to 2018 are illustrated in Figure 1.

Figure 1: World Cup Titles within 1930-2018.

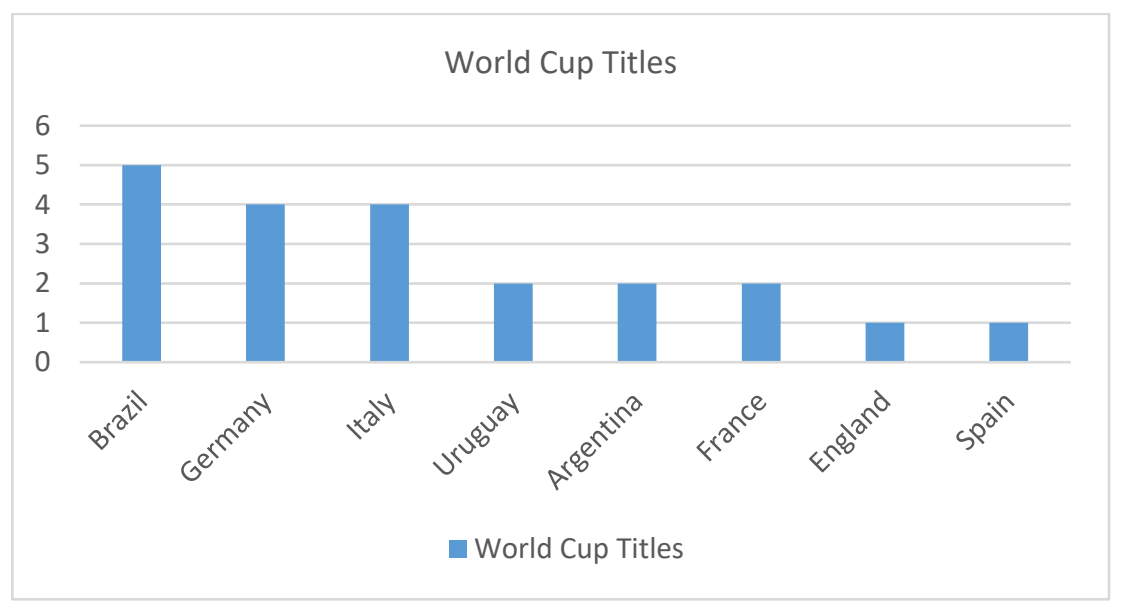

Source: https://www.totalsportek.com/football/fifa-world-cup-winners (Access Date: 17.07.2018).

\section{Methodology}

Charnes et al. (1978) introduced non parametric efficiency measurement method dubbed as DEA. Their formulation assumed constant returns to scale. Their formulation enabled multiple input and outputs. Banker et al. (1984) extended the model assuming variable returns to scale (Ruggiero, 2011: 1). 
Efficiency via DEA model can be measured either utilizing input orientation or output orientation. The input orientation tries to minimize input level keeping output level constant. The output orientation tries to obtain maximum output level holding input level constant (Ruggiero, 2011: 2).

\subsection{CCR Model}

CCR model assumed that production technology indicating constant returns to scale (CRS) (Paradi et al, 2018: 6). CCR model might be evaluated as the reduction of the multiple-output/multiple-input situation for each DMU to that of a single virtual output and virtual input (Cooper et al, 2011: 7).

The mathematical programming approach is used to achieve the values for the input "weights" (vi) $\{\mathrm{i}=\mathrm{I}, \ldots, \mathrm{m})$ and the output "weights" (ur) $\{\mathrm{r}=\mathrm{I}, \ldots, \mathrm{s})$ as variables The model structure is given as the following (Cooper et al., 2006: 23):

$\operatorname{Max} u_{u, v}^{\theta}=\frac{u_{1} y_{1 o}+u_{2} y_{2 o+\cdots \ldots}+u_{s} y_{s o}}{v_{1} x_{1 o}+v_{2} x_{2 o+\cdots \ldots+v_{m} x_{m o}}}$

subject to $\frac{u_{1} y_{1 j}+u_{2} y_{2 o+\cdots \ldots}+u_{s} y_{s j}}{v_{1} x_{1 j}+\cdots . . v_{m} x_{m j}} \leq 1 \quad(\mathrm{j}=1,2 \ldots \ldots)$

$u_{1}, u_{2}, \ldots \ldots, u_{m} \quad \geq 0$

$v_{1}, v_{2}, \ldots \ldots, v_{m} \geq 0$

The constraints correspond to the ratio of "virtual output" vs. "virtual input" can't exceed "1" for each DMU. The objective is to attain the weights $\left(v_{i}\right)$ and $\left(u_{r}\right)$ which maximize the ratio of, the DMU being analyzed.

\subsection{BCC Model}

Banker et al. (1984) suggested a radial DEA model where the production technology displays variable returns to scale (VRS). The input-oriented version of the BCC model is presented the following (Cooper et al., 2006: 91) :

$$
\begin{aligned}
& \text { Min } \\
& \theta_{b}, \lambda \\
& \text { Subject to } \theta_{b} x_{0}-x_{\lambda} \geq 0 \\
& Y_{\lambda} \geq y_{0} \\
& e_{\lambda}=1 \\
& \lambda \geq 0
\end{aligned}
$$

where $\theta_{b}$ is a scalar, e a row vector with all elements unity and $\lambda$ corresponds to a column vector with all elements non-negative. Considering the condition $\lambda_{\mathrm{j}}>0$, for all $j$, this stipulates a convexity constraint on permissible ways in which the observations for the DMUs can be merged. 


\subsection{Scale Efficiency}

CCR model provides the technical efficiency (TE) and BCC model can provide the pure technical efficiency score (PTE). Scale efficiency (SE) which projects the potential productivity that can be achieved by acquiring an optimum size of a DMU can be measured depending on technical efficiency and pure technical efficiency scores (Toma et al. 2015: 706):

$$
\text { Scale efficiency }=\frac{\text { Technical efficiency }}{\text { Pure technical efficiency }}
$$

By comparing the efficiency scores calculated from both CCR and BCC models, the effects stemming from unsuitable scale can be detected. The detected sources of inefficiency can make possible to project proper alternatives to thrive the performance of a DMU (Cook and Zhu, 2017: 120).

\subsection{Super efficiency DEA model}

The conventional CCR model has inefficient distinction when DMUs are on the frontier of production which generally lead to hardship in additional assessment and comparison between DMUs. In order to overcome the deficiency of CCR model and appraise DMUs efficiencies thoroughly, Andersen and Petersen (1993), introduced super efficiency model which can separate efficiency among DMUs (Yang et al, 2015: 15).

Super efficiency model can be formulated as follows (Zhu, 2014: 206):

$$
\begin{aligned}
& \text { Mint } \theta^{\text {super }} \\
& \text { s.t. } \sum_{\substack{j \neq 0 \\
j=1}}^{n} x_{i j \lambda_{j}} \leq \theta^{\text {super }} X_{i o} \quad \mathrm{i}=1,2 \ldots \mathrm{m} \\
& \sum_{\substack{j \neq 0 \\
j=1}}^{n} y_{r j \lambda_{j}} \geq y_{\text {ro }} \quad \quad \mathrm{r}=1,2, \ldots \ldots \mathrm{s} \\
& \lambda_{j} \geq 0 \quad \mathrm{j} \neq 0
\end{aligned}
$$

If we add the following condition, we can get the variable returns to scale (VRS) model (Tone, 2017: 29):

$\sum_{j \neq 0}^{n} \lambda_{j}=1$

\section{Empirical Results}

In the empirical studies, TE, PTE and SE values and super efficiency scores are measured and evaluated for national teams participating in 2014 World Cup. Selecting the appropriate inputs and outputs has a critical role in DEA process. In this respect, the appropriate inputs and outputs are determined taking into considerations available studies. In this study, passes completed, attempts on target, possession were the selected inputs. Scored goals are selected as output. The data used in the DEA 
applications is provided from FIFA web site. ${ }^{1}$ Firstly descriptive statistics are illustrated in Table 1.

Table 1. Descriptive Statistics.

\begin{tabular}{|c|c|c|c|c|c|}
\hline \multicolumn{2}{|c|}{ Decision Variables } & Average & Maximum & Minimum & $\begin{array}{c}\text { Standart } \\
\text { Deviation }\end{array}$ \\
\hline \multirow{3}{*}{ Inputs } & $\begin{array}{c}\text { Attempts on } \\
\text { Target }\end{array}$ & 31.5 & 72 & 12 & 17.32 \\
\cline { 2 - 6 } & Possession & 49.7 & 59.1 & 35.5 & 5.22 \\
\cline { 2 - 6 } & $\begin{array}{c}\text { Passes } \\
\text { Completed }\end{array}$ & 1582 & 4157 & 604 & 763 \\
\hline Outputs & Goals Scored & 5.34 & 18 & 1 & 4.03 \\
\hline
\end{tabular}

In the first part of the empirical study, both CCR and BCC Models have been implemented for the teams then SE scores have been measured for the selected DMUs. The efficiency results regarding 2014 World Cup are illustrated in Table 2.

Table 2. Efficiency Results for Teams Participating in World Cup.

\begin{tabular}{|c|c|c|c|c|c|}
\hline \multirow[b]{2}{*}{ DMUs } & \multicolumn{2}{|c|}{ TE Scores } & \multicolumn{2}{|c|}{ PTE Scores } & \multirow{2}{*}{$\begin{array}{c}\text { Scale } \\
\text { Efficiency }\end{array}$} \\
\hline & CCR & $\begin{array}{c}\text { Super } \\
\text { Efficiency }\end{array}$ & $\mathrm{BCC}$ & $\begin{array}{c}\text { Super } \\
\text { Efficiency }\end{array}$ & \\
\hline Germany & 1.000 & 1.056 & 1.000 & 1.000 & 1.000 \\
\hline Netherlands & 1.000 & 1.020 & 1.000 & 1.054 & 1.000 \\
\hline Colombia & 1.000 & 1.417 & 1.000 & 1.573 & 1.000 \\
\hline Brazil & 0.728 & 0.728 & 0.869 & 0.869 & 0.837 \\
\hline France & 0.680 & 0.680 & 0.813 & 0.813 & 0.836 \\
\hline Argentina & 0.500 & 0.500 & 0.800 & 0.800 & 0.625 \\
\hline Algeria & 1.000 & 1.008 & 1.000 & 1.110 & 1.000 \\
\hline Switzerland & 0.561 & 0.561 & 0.846 & 0.846 & 0.663 \\
\hline Croatia & 0.824 & 0.824 & 1.000 & 1.001 & 0.824 \\
\hline Chile & 0.993 & 0.993 & 1.000 & 1.053 & 0.993 \\
\hline Belgium & 0.441 & 0.441 & 0.792 & 0.792 & 0.556 \\
\hline Mexico & 0.714 & 0.714 & 0.833 & 0.833 & 0.857 \\
\hline USA & 0.583 & 0.583 & 0.871 & 0.871 & 0.670 \\
\hline Costa Rica & 0.873 & 0.873 & 1.000 & 1.009 & 0.873 \\
\hline $\begin{array}{c}\text { Bosnia } \\
\text { Herzegovina }\end{array}$ & 0.421 & 0.421 & 0.720 & 0.720 & 0.584 \\
\hline Ivory Coast & 0.422 & 0.422 & 0.710 & 0.710 & 0.594 \\
\hline Ghana & 0.526 & 0.526 & 0.796 & 0.796 & 0.661 \\
\hline Spain & 0.547 & 0.547 & 0.708 & 0.708 & 0.772 \\
\hline Portugal & 0.451 & 0.451 & 0.775 & 0.775 & 0.582 \\
\hline Uruguay & 0.436 & 0.436 & 0.832 & 0.832 & 0.524 \\
\hline Ecuador & 0.526 & 0.526 & 0.955 & 0.955 & 0.551 \\
\hline South Korea & 0.394 & 0.394 & 0.732 & 0.732 & 0.538 \\
\hline Australia & 0.674 & 0.674 & 1.000 & 1.057 & 0.674 \\
\hline Greece & 0.316 & 0.316 & 0.782 & 0.782 & 0.404 \\
\hline Nigeria & 0.296 & 0.296 & 0.768 & 0.768 & 0.386 \\
\hline Italia & 0.393 & 0.393 & 0.813 & 0.812 & 0.484 \\
\hline
\end{tabular}

${ }^{1}$ FIFA official web site www.fifa.com (Access Date: 20.06.2018). 


\begin{tabular}{|c|c|c|c|c|c|}
\hline \multirow{2}{*}{ DMUs } & \multicolumn{2}{|c|}{ TE Scores } & \multicolumn{2}{c|}{ PTE Scores } & \multirow{2}{*}{$\begin{array}{c}\text { Scale } \\
\text { Efficiency }\end{array}$} \\
\cline { 2 - 5 } & CCR & $\begin{array}{c}\text { Super } \\
\text { Efficiency }\end{array}$ & BCC & $\begin{array}{c}\text { Super } \\
\text { Efficiency }\end{array}$ & 0.387 \\
\hline Russia & 0.274 & 0.274 & 0.707 & 0.707 & 0.470 \\
\hline England & 0.331 & 0.331 & 0.704 & 0.704 & 0.453 \\
\hline Japan & 0.226 & 0.226 & 0.654 & 0.653 & 0.345 \\
\hline Iran & 0.262 & 0.262 & 1.000 & 1.429 & 0.262 \\
\hline Honduras & 0.185 & 0.185 & 0.751 & 0.751 & 0.246 \\
\hline Cameroon & 0.185 & 0.185 & 0.807 & 0.807 & 0.229 \\
\hline Average & $\mathbf{0 . 5 5 5}$ & & $\mathbf{0 . 8 4 4}$ & & $\mathbf{0 . 6 3 8}$ \\
\hline
\end{tabular}

As shown in Table I, CCR analyses have revealed that 4 teams are efficient. The teams have the mean technical efficiency as 55.50. According to BCC Model, 9 teams have pure technical efficiencies and the mean PTE level is 0.84 . Table I also gives information about scale efficiency. Four teams are found scale efficient. Besides, 28 teams have found scale inefficient, which means that these teams are not operation under optimal scale. Table 3 summarizes improvement ratios of the teams for DEA models.

Table 3. Improvement Ratios for World Cup Teams.

\begin{tabular}{|c|c|c|c|}
\hline \multicolumn{2}{|c|}{ Decision Variables } & CCR Model & BCC Model \\
\hline \multirow{4}{*}{ Inputs } & $\begin{array}{c}\text { Attempts on } \\
\text { Target }\end{array}$ & -0.453 & -0.217 \\
\cline { 2 - 4 } & Possession & -0.527 & -0.160 \\
\cline { 2 - 4 } & $\begin{array}{c}\text { Passes } \\
\text { Completed }\end{array}$ & -0.495 & -0.197 \\
\hline Outputs & Goals Scored & 0 & 0 \\
\hline
\end{tabular}

Inputs for CCR Model have to be decreased within $41.31 \%-49.56 \%$ range and inputs for BCC Model should be diminished by $16.09 \%-21.76 \%$. However, on the basis of outputs, both CCR and BCC Model would not recommend an output decrease.

Secondly, World Cup teams have separated into two equal groups depending on their FIFA ranking. Then two equal group are analyzed separately. Table 4 and 5 reveal technical efficiency and pure technical efficiency and scale efficiency for the first and last 16 teams respectively.

Table 4. Efficiency Results for First 16 Teams.

\begin{tabular}{|c|c|c|c|c|c|}
\hline \multirow{2}{*}{ DMUs } & \multicolumn{2}{|c|}{ TE Scores } & \multicolumn{2}{c|}{ PTE Scores } & \multirow{2}{*}{$\begin{array}{c}\text { Scale } \\
\text { Efficiency }\end{array}$} \\
\cline { 2 - 5 } & CCR & $\begin{array}{c}\text { Super } \\
\text { Efficiency }\end{array}$ & BCC & $\begin{array}{c}\text { Super } \\
\text { Efficiency }\end{array}$ & \\
\hline Germany & 1.000 & 1.056 & 1.000 & 1.000 & 1.000 \\
\hline Netherlands & 1.000 & 1.020 & 1.000 & 1.054 & 1.000 \\
\hline Colombia & 1.000 & 1.498 & 1.000 & 1.585 & 1.000 \\
\hline Brazil & 0.727 & 0.727 & 0.899 & 0.899 & 0.809 \\
\hline France & 0.679 & 0.679 & 0.856 & 0.856 & 0.794 \\
\hline Argentina & 0.499 & 0.499 & 0.879 & 0.879 & 0.568 \\
\hline Switzerland & 0.560 & 0.560 & 0.959 & 0.959 & 0.590 \\
\hline Croatia & 0.826 & 0.826 & 1.000 & 1.287 & 0.826 \\
\hline
\end{tabular}




\begin{tabular}{|c|c|c|c|c|c|}
\hline \multirow{2}{*}{ DMUs } & \multicolumn{2}{|c|}{ TE Scores } & \multicolumn{2}{c|}{ PTE Scores } & \multirow{2}{*}{$\begin{array}{c}\text { Scale } \\
\text { Efficiency }\end{array}$} \\
\cline { 2 - 5 } & CCR & $\begin{array}{c}\text { Super } \\
\text { Efficiency }\end{array}$ & BCC & $\begin{array}{c}\text { Super } \\
\text { Efficiency }\end{array}$ & \\
\hline Chile & 1.000 & 1.000 & 1.000 & 1.211 & 1.000 \\
\hline Belgium & 0.440 & 0.440 & 0.910 & 0.910 & 0.484 \\
\hline Mexico & 0.719 & 0.719 & 1.000 & 1.020 & 0.719 \\
\hline Spain & 0.550 & 0.550 & 0.884 & 0.884 & 0.630 \\
\hline Portugal & 0.452 & 0.452 & 0.983 & 0.983 & 0.474 \\
\hline Uruguay & 0.436 & 0.436 & 1.000 & 1.048 & 0.436 \\
\hline Italy & 0.395 & 0.395 & 1.000 & 1.308 & 0.395 \\
\hline England & 0.333 & 0.333 & 1.000 & 1.019 & 0.333 \\
\hline Average & $\mathbf{0 . 6 6 3}$ & & $\mathbf{0 . 9 5 7}$ & & $\mathbf{0 . 6 9 1}$ \\
\hline
\end{tabular}

As illustrated in the Table III, CCR model results show that 4 teams are found technical efficient. 12 teams are found inefficient. The average technical efficiency for the teams is 0.663. Chile is also efficient when teams are separated into two groups. According to super efficiency results, Colombia is found the most efficient team among first 16 teams. BCC model results show that 9 teams are found pure technical efficient and the mean PTE level corresponds to 0.957. 4 teams have shown scale efficiency and operate under optimal scale while 12 teams have shown scale inefficiency.

Table 5. Efficiency Results for Last 16 Teams

\begin{tabular}{|c|c|c|c|c|c|}
\hline \multirow{2}{*}{ DMUs } & \multicolumn{2}{|c|}{ TE Scores } & \multicolumn{2}{c|}{ PTE Scores } & \multirow{2}{*}{$\begin{array}{c}\text { Scale } \\
\text { Efficiency }\end{array}$} \\
\cline { 2 - 5 } & CCR & $\begin{array}{c}\text { Super } \\
\text { Efficiency }\end{array}$ & BCC & $\begin{array}{c}\text { Super } \\
\text { Efficiency }\end{array}$ & \\
\hline Algeria & 1.000 & 1.716 & 1.000 & 1.000 & 1.000 \\
\hline USA & 0.654 & 0.654 & 0.871 & 0.871 & 0.751 \\
\hline Costa Rica & 0.873 & 0.873 & 1.000 & 1.009 & 0.873 \\
\hline $\begin{array}{c}\text { Bosnia } \\
\text { Herzegovina }\end{array}$ & 0.483 & 0.483 & 0.720 & 0.720 & 0.671 \\
\hline $\begin{array}{c}\text { Cote de } \\
\text { Ivory }\end{array}$ & 0.561 & 0.561 & 0.739 & 0.739 & 0.759 \\
\hline Ghana & 0.640 & 0.640 & 0.843 & 0.843 & 0.759 \\
\hline Ecuador & 0.640 & 0.640 & 1.000 & 1.002 & 0.640 \\
\hline South Korea & 0.444 & 0.444 & 0.732 & 0.732 & 0.606 \\
\hline Australia & 0.673 & 0.673 & 1.000 & 1.078 & 0.673 \\
\hline Greece & 0.397 & 0.397 & 0.783 & 0.783 & 0.507 \\
\hline Nigeria & 0.369 & 0.369 & 0.768 & 0.768 & 0.480 \\
\hline Russia & 0.289 & 0.289 & 0.707 & 0.707 & 0.410 \\
\hline Japan & 0.267 & 0.267 & 0.654 & 0.654 & 0.409 \\
\hline Iran & 0.282 & 0.282 & 1.000 & 1.429 & 0.282 \\
\hline Honduras & 0.184 & 0.184 & 0.860 & 0.860 & 0.246 \\
\hline Cameroon & 0.194 & 0.194 & 0.807 & 0.807 & 0.240 \\
\hline Average & $\mathbf{0 . 4 9 7}$ & & $\mathbf{0 . 8 3 5}$ & & $\mathbf{0 . 5 8 2}$ \\
\hline
\end{tabular}

As illustrated in the Table 5, CCR model results illustrates that only Algeria is found technical efficient. 15 teams are found inefficient. The average technical efficiency for the teams is 0.497 . BCC model results show that 5 teams are found pure technical efficient 
and the mean PTE level corresponds to 0.835 . The results also reveal that the most efficient team in BCC Super efficiency model is Iran.

\section{Conclusions}

This study comprises the efficiency analysis of World Cup teams by DEA method which is a widely used mathematical programming technique. The empirical study has revealed significant efficiency results for World Cup teams.

Some general results have emerged. Our empirical results are consistent with EspitiaEscuer and Garcia-Cebrian (2004) and Zambom-Ferraresi (2017) as an instance, efficient teams don't necessarily finish the tournament at the top level. This result is consistent with Espitia-Escuer and Garcia-Cebrian (2004), Zambom-Ferraresi (2017) et al. In a similar vein, some teams accomplishing on the field performed relatively low efficient sores. This result is consistent with Guzman and Morrow (2007), Pyatunin et al, (2016).

The efficiency results reveal that World Cup winner Germany is efficient on both models. TE scores among the inefficient teams range from 0.185 for Cameroon to 0.992 for Chile. This finding reveals that Cameroon and Chile can potentially decrease their actual input grades by $81.5 \%$ and $0.01 \%$ respectively while leaving their output grades constant. We observe that average TE score is 0.55 .

Thus, it is obvious from the results that the same level of outputs in teams could be produced with 45 percent less inputs. On the other hand, only four teams are found technically efficient out of 32 teams while nine teams are found pure efficient. The scores of PTE are found higher than the scores of TE. These results are in line with related DEA literature.

Besides, four more teams are found efficient in BCC model when teams are divided into equal groups. In further, Germany, Netherland, Colombia and Algeria are found scale efficient. This result illustrates that these teams have determined optimal size of operation. Out of these 32 teams, 3 teams have PTE score smaller than SE score. This result points out that the inefficiency in resource utilization in these 3 teams namely France, Mexico and Spain is mainly due to managerial inefficiency in comparison to scale inefficiency.

In this regard, we may conclude that DEA approach can provide significant results in analyzing the efficiency level of football teams.

\section{References}

Andersen, P. and Petersen, N.C., (1993). A Procedure for Ranking Efficient Units in Data Envelopment Analysis. Management Science Vol: 39, s.1261-1264.

Banker, R. D., Charnes, A., and Cooper, W. W. (1984). Some models for Estimating Technical and Scale Inefficiencies in Data Envelopment Analysis. Management Science, Vol: 30(9), s.1078-1092. 
Barros, C. P., and Garcia-del-Barrio, P. (2008). "Efficiency Measurement of the English Football Premier League with a Random Frontier Model". Economic Modelling, Vol: 25(5), s.994-1002.

Barros, C. P., and Leach, S. (2006). Performance evaluation of the English Premier Football League with data envelopment analysis. Applied Economics, Vol: 38(12), s.1449-1458.

Boscá, J. E., Liern, V., Martínez, A., and Sala, R. (2009). Increasing Offensive or Defensive Efficiency? An analysis of Italian and Spanish football. Omega, Vol: 37(1), s.63-78.

Charnes, A., Cooper, W. W., and Rhodes, E. (1978). Measuring the Efficiency of Decision Making Units. European Journal of Operational Research, Vol: 2(6), s.429-444.

Cook, W. D., Tone, K., and Zhu, J. (2014). "Data Envelopment Analysis: Prior to Choosing a Model". Omega, Vol: 44, s.1-4.

Cook, W. D., and Zhu, J. (2017) Data Envelopment Analysis A Handbook on the Modeling of Internal Structures and Networks, Vol. 208, Springer.

Cooper, W. W., Seiford, L., and Tone, K. (2006). Data Envelopment Analysis A Comprehensive Text with Models, Applications, References and DEA-Solver Software, Springer.

Cooper, W. W., Seiford, L., Zhu, J. (2011). Handbook on Data Envelopment Analysis, Springer Science Business Media.

Espitia-Escuer, M., and Garcla-Cebrian, L. I. (2004). Measuring the Efficiency of Spanish First-Division Soccer Teams. Journal of Sports Economics, Vol: 5(4), s.329-346.

García-Sánchez, I. M. (2007). Efficiency and Effectiveness of Spanish Football Teams: A Three-Stage-DEA Approach. Central European Journal of Operations Research, Vol: 15(1), s.21-45.

Guzmán, I., and Morrow, S. (2007). Measuring Efficiency and Productivity in Professional Football Teams: Evidence from the English Premier League. Central European Journal of Operations Research, Vol: 15(4), s.309-

Iribarren, D., Vázquez-Rowe, I., Rugani, B., and Benetto, E. (2014). On the Feasibility of Using Energy Analysis as a Source of Benchmarking Criteria through Data Envelopment Analysis: A Case Study for Wind Energy. Energy Vol: 67, s.527-537.

Kao, C., and Liu, S. T. (2014). Multi-Period Efficiency Measurement in data Envelopment Analysis: The Case of Taiwanese Commercial Banks. Omega, Vol: 47, s.90-98.

Kern, A., Schwarzmann, M., and Wiedenegger, A. (2012). Measuring the Efficiency of English Premier League Football: A Two-Stage Data Envelopment Analysis Approach. Sport, Business and Management: An International Journal, Vol: 2(3), s.177-195.

Paradi, J. C., Sherman H. D., Tam, K., F. (2018). Data EnvelopmentAnalysis in the Financial Services Industry, Springer International Publishing. 
Pyatunin, A. V., Vishnyakova, A. B., Sherstneva, N. L., Mironova, S. P., Dneprov, S. A., and Grabozdin, Y. P. (2016). The Economic Efficiency of European Football Clubs--Data Envelopment Analysis (DEA) Approach. International Journal of Environmental and Science Education, Vol: 11(15), s.7515-7534.

Ruggiero, J. (2011). Frontiers in Major League Baseball, Sports Economics, Management and Policy, Springer.

Sport England Main Report (2001). Performance Measurement for the Development of Sport 1-78.

Tiedemann, T., Francksen, T., and Latacz-Lohmann, U. (2011). Assessing the Performance of German Bundesliga Football Players: A Non-Parametric Metafrontier Approach. Central European Journal of Operations Research, Vol: 19(4), s.571-587.

Toma, E., Dobre, C., Dona, I., and Cofas, E. (2015). DEA Applicability in Assessment of Agriculture Efficiency on Areas with Similar Geographically Patterns. Agriculture and Agricultural Science Procedia, Vol: 6, s.704-711.

Tomlinson, A., and Young, C. (2006). National Identity and Global Sports Events: Culture, Politics, and Spectacle in the Olympics and the Football World Cup, Suny Press.

Tone, K. (Ed.). (2017). Advances in DEA Theory and Applications: with Extensions to Forecasting Models. John Wiley \& Sons.

Villa, G., and Lozano, S. (2016). Assessing the Scoring Efficiency of a Football Match. European Journal of Operational Research, Vol.255 (2), s.559-569.

Wheelwright, W. (2014). 50 Quick Facts about World Cup, Andrews UK Limited.

Yang, L., Ouyang, H., Fang, K., Ye, L., and Zhang, J. (2015). Evaluation of Regional Environmental Efficiencies in China Based on Super-Efficiency-DEA. Ecological Indicators, 51, 13-19.

Zambom-Ferraresi, F., García-Cebrián, L. I., Lera-López, F., and Iráizoz, B. (2017). Performance Evaluation in the UEFA Champions League. Journal of Sports Economics, 18(5), 448-470.

Zhu, J. (2014). Quantitative Models for Performance Evaluation and Benchmarking: Data Envelopment Analysis with Spreadsheets Vol. 213 Springer.

https://www.totalsportek.com/football/fifa-world-cup-winners. (Access Date: 17.07.2018).

www. fifa.com ${ }^{1}$ FIFA official web site (Access Date: 20.06.2018). 